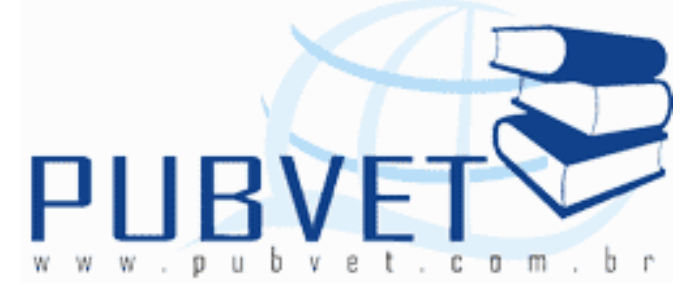

PUBVET, Publicações em Medicina Veterinária e Zootecnia.

\title{
Densidades nutricionais para frangos de corte estressados por calor cíclico
}

Melina da Conceição Macêdo da Silva ${ }^{1}$, Agustinho Valente de Figueirêdo ${ }^{2}$, Yânez André Gomes Santana ${ }^{1}$, Domingos Urquiza de Carvalho Filho ${ }^{1}$, Elvania Maria da Silva Costa ${ }^{1}$, Daniela Cristina Pereira Lima ${ }^{1}$, Tatiele Pereira Araújo ${ }^{3}$, Antônio de Carvalho Pereira ${ }^{3}$, Samira Souza Melo ${ }^{4}$

${ }^{1}$ Pós-Graduando em Ciência Animal, Universidade Federal do Piauí (UFPI)

${ }^{2}$ Professor Dr., Universidade Federal do Piauí (UFPI).

${ }^{3}$ Graduando, Universidade Federal do Piauí (UFPI).

${ }^{4}$ Pós- Graduanda em Engenharia de Alimentos, Universidade de São Paulo (USP)

\section{Resumo}

A avicultura brasileira tem apresentado altos índices de crescimento. Seu bem principal, o frango, conquistou os mais exigentes mercados. O Brasil buscou modernização e empregou instrumentos como o manejo adequado do aviário, sanidade, alimentação balanceada, melhoramento genético e produção integrada. Em períodos quentes, há uma redução no consumo de ração que traz prejuízos evidentes ao desempenho das aves e estratégias nutricionais podem ser utilizadas como ferramentas, além de modificações necessárias em ambiência, como a diminuição do incremento calórico proporcionado por alguns alimentos, que podem auxiliar na manutenção de um estado corporal 
confortável, para que as aves possam exercer todo seu potencial produtivo. No entanto alguns produtores, em regiões com temperaturas elevadas, usam altos níveis energéticos nas rações como estratégia nutricional, prática essa que muitas vezes aumentam o custo das rações. A realização de pesquisas quanto ao desempenho das aves em regiões com temperaturas elevadas e o estresse térmico provocado nas mesmas é necessária, sendo extremamente importante para adaptação às normas do mercado internacional de qualidade exigida.

Termos para indexação: estratégia nutricional, manejo, produção.

\title{
Diets with different nutritional broiler stressed by cyclic heat
}

\begin{abstract}
The Brazilian poultry industry has delivered high rates of growth. His main asset, chicken, conquered the most demanding markets. Brazil has sought to modernize instruments and employed as the proper management of the aviary, health, balanced nutrition, breeding and integrated production. In hot periods, there is a reduction in feed intake that causes damage evident on bird performance and nutritional strategies can be used as tools, and necessary changes in ambience, such as decreased caloric increment provided by some foods that can help maintain a comfortable body condition, so that the birds can exercise all their productive potential. However some producers in regions with high temperatures, high levels of energy use in feed as a nutritional strategy, a practice that often increase the cost of feed. Performing research on the birds performance in regions with high temperatures and thermal stress caused the same is required, it is extremely important to adapt to international market standards of quality required.
\end{abstract}

Index terms: nutritional strategy, management, production. 
SILVA, M.C.M. et al. Densidades nutricionais para frangos de corte estressados por calor cíclico. PUBVET, Londrina, V. 7, N. 6, Ed. 229, Art. 1517, Março, 2013.

\section{Introdução}

Nas últimas três décadas, a avicultura brasileira tem apresentado altos índices de crescimento. Seu bem principal, o frango, conquistou os mais exigentes mercados. O Brasil buscou modernização e empregou instrumentos como o manejo adequado do aviário, sanidade, alimentação balanceada, melhoramento genético e produção integrada, tornando-se o terceiro produtor mundial e líder em exportação. A produção de frangos de corte apresenta grandes avanços nos aspectos nutricional, genético e de manejo, o que explica e torna uma das atividades de produção animal que mais se desenvolveram. Isso se deve, basicamente, à busca de novos sistemas de criação com maior produtividade no menor espaço de tempo. Segundo o relatório anual da União Brasileira de Avicultura - UBABEF (2011), a produção de carne de frango chegou a 12, 230 milhões de toneladas em 2010, em um crescimento de $11,38 \%$ em relação a 2009 , quando foram produzidas 10,980 milhões de toneladas.

A parceria entre indústria e avicultores também contribuiu para a excelência técnica em todas as etapas da cadeia produtiva, resultando em reduzidos custos de transação e melhoria da qualidade, que atende às demandas de todo o mundo. A taxa de crescimento de produção da carne de frango, por exemplo, deve alcançar $4,22 \%$, e as exportações tendo expansão prevista de 5,62\% ao ano; o Brasil deverá continuar na liderança mundial, segundo o Ministério da Agricultura, até 2020, a expectativa é que a produção nacional de carne de frango atingirá $48,1 \%$ das exportações mundiais (BRASIL, 2011).

Para atingir melhores resultados econômicos e produtivos, a avicultura de corte moderna, precisa avançar também nos aspectos ambientais, que interferem diretamente na expressão do potencial das aves (LANA et al., 2001). Para isso as recomendações sobre nutrição e alimentação de frangos de corte devem ser realizadas considerando-se a temperatura ambiente, observando-se a faixa de conforto térmico das aves em crescimento, adequada 
SILVA, M.C.M. et al. Densidades nutricionais para frangos de corte estressados por calor cíclico. PUBVET, Londrina, V. 7, N. 6, Ed. 229, Art. 1517, Março, 2013.

para atender as exigências nutricionais e energéticas das aves em ambiente de estresse por calor ou frio.

Em períodos quentes, a redução no consumo de ração traz prejuízos evidentes ao desempenho das aves e estratégias nutricionais podem ser utilizadas como ferramentas, além de modificações necessárias em ambiência, como a diminuição do incremento calórico proporcionado por alguns alimentos, que podem auxiliar na manutenção de um estado corporal confortável, para que as aves possam exercer todo seu potencial produtivo.

A alimentação normalmente utilizada na produção de frangos de corte, no Brasil, segue as recomendações de Rostagno et al. (2011). No entanto alguns produtores, em regiões com temperaturas elevadas, usam altos níveis energéticos nas rações como estratégia nutricional para manter o produto competitivo no mercado, ao mesmo tempo procuram alternativas para reduzir seus custos.

A expressão gênica, os efeitos ambientais e sanitários somente exercem uma importância primária sobre o desempenho animal caso as exigências nutricionais sejam devidamente alcançadas. No entanto, o fornecimento excessivo de nutrientes pode, ainda, ser mais dispendiosa que as deficiências, porque chega a limitar a produção e, concomitantemente, pode incrementar o custo de produção (ARAújo et al., 2001).

Grande parte das dietas formuladas para aves são produzidas à base de milho e farelo de soja, considerados alimentos de excelente digestibilidade e disponibilidade de aminoácidos, representando mais de $70 \%$ da proteína dietética das rações. Entretanto a soja integral tem sido utilizada em substituição ao farelo de soja, por apresentar proteína de alta qualidade e ser uma rica fonte de energia, mas para sua utilização a inativação dos fatores antinutricionais, torna-se necessária, sendo feita por meio de processamentos como tostagem e extrusão (BRITO, 2006).

O componente que mais influencia o custo de produção nas rações para frangos de corte, é a energia. Pois, ocasiona um efeito no consumo da ração a ser ingerida, assumi grande importância no desenvolvimento corporal dos 
animais, interferindo na utilização dos nutrientes disponíveis na dieta, sendo estes necessários ao atendimento das exigências dos animais nos diferentes estágios produtivos (PEARSON \& HERRON, 2002).

Em regiões de clima quente o consumo de ração tem o valor energético como o primeiro fator controlador do consumo da ave. Contudo, ajustes da densidade nutricional das rações podem se constituir como alternativa para permitir o atendimento das necessidades nutricionais das aves e também minimizar alguns dos problemas decorrentes da redução do seu consumo em climas quentes.

Portanto, a realização de pesquisas quanto ao desempenho das aves em regiões com temperaturas elevadas e o estresse térmico provocado nas mesmas, é necessária e deve ser feita, sendo extremamente importante para adaptação às normas do mercado internacional de qualidade exigida, sempre buscando recursos alternativos para melhoria, sem aumentar os custos de produção.

\section{Influência das condições ambientais na produção de frango de corte}

A temperatura ambiente é considerada o fator físico de maior efeito no desempenho de frangos de corte, já que exerce grande influência no consumo de ração e, com isto, afeta diretamente o ganho de peso e a conversão alimentar destes animais. Segundo Silva (2000), quando um animal é colocado em um determinado ambiente, as trocas térmicas que ocorrem com ele dependem das condições ambientais em que se encontram. Se o ambiente apresenta temperaturas mais elevadas do que aquelas nas quais o organismo opera melhor, então há uma condição de estresse térmico, ocasionando perdas produtivas e de energia.

Quando as aves são submetidas a temperaturas ambientais fora da zona de termoneutralidade respondem com comportamentos alimentares e atitudes físicas características. Ao elevar a temperatura corporal, em função do aumento na temperatura ambiental, as aves aumentam a frequência 
SILVA, M.C.M. et al. Densidades nutricionais para frangos de corte estressados por calor cíclico. PUBVET, Londrina, V. 7, N. 6, Ed. 229, Art. 1517, Março, 2013.

respiratória e reduzem o consumo de ração, na tentativa de manter a temperatura corporal dentro de limites fisiológicos, restringindo o consumo ideal de nutrientes. Sabe-se que o consumo médio de água geralmente corresponde a duas vezes o consumo alimentar. Contudo, essa relação aumenta em condições de temperaturas extremamente altas.

Para atingir o mercado consumidor em grande escala, a produção de frangos de corte visa o rápido ganho de peso com a utilização eficiente da alimentação por estes animais. Entretanto, as exigências nutricionais dos frangos, para torná-los excelentes conversores da alimentação em carne, podem variar de acordo com as zonas climáticas e as fontes de alimento. A quantidade de alimento fornecido às aves à vontade não significa retorno econômico (BARBOSA, 2008). Desta forma, torna-se necessário uma maior atenção para fatores como as condições do ambiente e alimentação, visando obter uma produção e produtividade compensatórias.

$\mathrm{O}$ animal tem seu comportamento fortemente influenciado pelo ambiente externo, assim como, fatores ligados ao próprio animal que pode servir para caracterizar as condições de conforto térmico suportadas por ele (MOURA, 2001).

As trocas térmicas com o meio são realizadas por quatro mecanismos principais: radiação, condução e convecção, denominada trocas sensíveis, caracterizadas por um diferencial de temperatura entre o animal e o ambiente, e através da evaporação, que constitui um dos mais importantes meios latentes de troca térmica dos animais (SILVA, 2008), podendo ser limitada pela umidade relativa do ar. No caso das aves, a perda de calor por evaporação, ocorre devido a um diferencial de pressão de vapor, através da ofegação (resfriamento evaporativo respiratório), uma vez que são desprovidas de glândulas sudoríparas, impossibilitando a sudação. As perdas de calor ocorrem pelos meios sensíveis, e em condições agudas de estresse, pelas formas latentes de troca térmica com o meio.

A temperatura recomendada para frangos de corte em um estágio inicial deve ser entre $32,0^{\circ} \mathrm{C}$ e $35,0^{\circ} \mathrm{C}$, e deve diminuir em $1,0^{\circ} \mathrm{C}$ a cada dois dias até 
SILVA, M.C.M. et al. Densidades nutricionais para frangos de corte estressados por calor cíclico. PUBVET, Londrina, V. 7, N. 6, Ed. 229, Art. 1517, Março, 2013.

atingir $22,0^{\circ} \mathrm{C}$. Para a terceira semana, a temperatura deve ser em torno de $22,0^{\circ} \mathrm{C} \pm 2,0^{\circ} \mathrm{C}$ (NICHOLSON et al., 2004). No caso do frango adulto, a temperatura ambiente deve ser de $21,1^{\circ} \mathrm{C}$, e a umidade de $50 \%$ (BARNWELL \& ROSSI, 2003).

O resultado do estresse térmico vem da interação entre temperatura do ar, calor e velocidade do vento (LIN et al., 2006). De acordo com Tao \& Xin (2003), quando a temperatura ambiente está na zona de termoneutralidade a temperatura interna de aves é mantida entre $41,2^{\circ} \mathrm{C}$ e $42,2^{\circ} \mathrm{C}$, quando a temperatura ambiente aumenta, mecanismos biofísicos são ativados. Se esses mecanismos não são suficientes para manter a homeotermia, a temperatura interna aumenta matando a ave pelo estresse térmico.

Partindo do princípio da teoria termoestática de que todos os animais homeotérmicos apresentam um consumo de alimento inversamente proporcional à temperatura do meio ambiente (NRC 1982). Alguns autores apontam que, entre os fatores ambientais, os térmicos são os que afetam diretamente as aves, pois comprometem sua função vital mais importante, que é a manutenção da homeotermia (WELKER, 2008; BARBOSA FILHO, 2009).

Além do desempenho, a temperatura ambiente modifica a retenção de energia, proteína e gordura no corpo animal e provoca diversas mudanças fisiológicas adaptativas, entre elas a modificação no tamanho dos órgãos em temperaturas abaixo da zona de conforto, o que também contribui para alterar a exigência nutricional das aves, visto que o gasto de energia pelos tecidos metabolicamente ativos, como fígado, intestino e rins é maior que aquele associado à carcaça (OLIVEIRA, 2006).

Em meio a outras respostas fisiológicas apresentadas pelas aves, quando expostas ao calor, incluem-se: a vasodilatação periférica que resulta no aumento da perda de calor não evaporativo. Assim, o calor é dissipado com o aumento da área da superfície (asas afastadas do corpo e penas eriçadas), ou com maior produção de urina. Outra resposta fisiológica é o aumento da taxa respiratória que resulta em perdas excessivas de dióxido de carbono $\left(\mathrm{CO}_{2}\right)$. Desta forma, a pressão parcial de $\mathrm{CO}_{2}\left(\mathrm{pCO}_{2}\right)$ diminui, levando à queda na 
concentração de ácido carbônico $\left(\mathrm{H}_{2} \mathrm{CO}_{3}\right)$ e hidrogênio $\left(\mathrm{H}^{+}\right)$. Em resposta os rins aumentam a exceção de $\mathrm{HCO}_{3}$ - e reduzem a excreção de $\mathrm{H}^{+}$na tentativa de manter o equilíbrio ácido-base da ave, apresentando risco de morte por alcalose respiratória (BORGES et al., 2003).

A redução no consumo de alimentos em temperaturas elevadas é o principal fator relacionado ao baixo desempenho de frangos de corte durante nos meses mais quentes do ano. O consumo alimentar é mais crítico no calor, devido aos níveis mais baixos de ingestão, que reduz o consum .,o ideal de nutrientes. Frangos de corte reduzem o consumo de ração em 1,7\% para cada aumento de $1^{\circ} \mathrm{C}$ quando a temperatura ambiente encontra-se dentro da faixa de $18^{\circ} \mathrm{C}$ a $32^{\circ} \mathrm{C}$. Essa redução pode chegar a $5 \%$ para cada aumento de $1^{\circ} \mathrm{C}$ quando a faixa de temperatura é de $32^{\circ} \mathrm{C}$ a $38^{\circ} \mathrm{C}$ (LANA et al., 2001). Vale ressaltar também que pesquisas relacionadas às exigências nutricionais, em sua maioria foram realizadas em sistemas de produção com temperaturas abaixo das encontradas no Nordeste do Brasil, de $26^{\circ} \mathrm{C}$ a $40^{\circ} \mathrm{C}$, durante o ano inteiro.

Uma das alternativas para compensar a redução no consumo de ração em ambientes de clima quente é substituir parte da energia da dieta fornecida pelos carboidratos, por energia proveniente de lipídeos, pois estes proporcionam menor incremento calórico aos animais, ou seja, o calor produzido pelo metabolismo da digestão e absorção dos nutrientes provenientes da alimentação, o que beneficia as aves criadas durante os meses de elevada temperatura ambiente, recuperando o consumo de energia e, consequentemente, o ganho de peso.

\section{Importância da densidade nutricional em dietas para frango de corte}

O crescente aumento na produção de frangos de corte nos últimos anos levou os nutricionistas a se empenharem em buscar soluções para atender às exigências nutricionais das aves, que, devido ao rápido crescimento e à 
SILVA, M.C.M. et al. Densidades nutricionais para frangos de corte estressados por calor cíclico. PUBVET, Londrina, V. 7, N. 6, Ed. 229, Art. 1517, Março, 2013.

consequente redução no tempo de abate, passaram a exigir alimentos de melhor qualidade.

O valor nutritivo dos alimentos está diretamente relacionado com sua composição química e energética, sendo importante o seu conhecimento para um correto balanceamento das rações. As dietas de frango de corte são compostas de proteínas, carboidratos, gorduras, vitaminas, minerais e água, embora todos os nutrientes desempenhem importante papel no metabolismo, pode-se ressaltar que a principal importância refere-se ao fornecimento de energia para mantença e produção.

O frango de corte atual apresenta maiores rendimentos de carne de peito e coxas+sobrecoxas, porém também deposita mais gordura na carcaça. Essas características estão diretamente ligadas à genética. Entretanto, a composição da carcaça pode sofrer influência pela nutrição, sexo e condições ambientais (KESSLER \& SNIZEK, 2001). Sendo assim, nas condições de clima quente, além de uma adequação dos níveis nutricionais à realidade climática, deve-se acompanhar as novas regras de manejo e a evolução genética das linhagens de corte.

A energia, obtida dos alimentos pelos animais, é utilizada prioritariamente para a manutenção dos processos vitais, como a respiração, manutenção da temperatura corporal e fluxo sanguíneo (OLIVEIRA NETO et al., 2000). Quando as moléculas orgânicas são oxidadas, a energia que é produzida como calor é usada nos processos metabólicos. (SAKOMURA \& ROSTAGNO, 2007).

A energia proveniente dos alimentos é um produto resultante da transformação dos nutrientes, pelo metabolismo animal e um dos fatores mais importantes a ser considerado na nutrição animal. É consenso entre os nutricionistas que a energia é um dos fatores limitantes do consumo e de que ela é utilizada nos mais diferentes processos, que envolvem desde a mantença das aves até o máximo potencial produtivo (FISCHER Jr. et al.,1998).

Outro aspecto importante na formulação de rações para aves é o conhecimento preciso do conteúdo energético dos alimentos, o que possibilita 
SILVA, M.C.M. et al. Densidades nutricionais para frangos de corte estressados por calor cíclico. PUBVET, Londrina, V. 7, N. 6, Ed. 229, Art. 1517, Março, 2013.

o fornecimento adequado de energia para aves em cada fase de seu ciclo (ALBINO et al., 1992). Deficiência de energia resulta em crescimento retardado ou perda total, diminuição de peso e morte eventual (MAYNARD et al., 1984).

Mesmo em ambientes com diferentes temperaturas, o consumo de energia depende das necessidades primárias das aves, dos ingredientes que participam da formulação da dieta e do nível de energia dietética (AMUTHA \& SAMINATHAN, 2003). Além de controlar o consumo de alimentos nas fases inicial, crescimento e final, a elevação da densidade calórica concorre também para o menor consumo de proteína e de outros nutrientes (SILVA JUNIOR et al., 2002).

A partir do conhecimento das exigências energéticas das aves, é possível ajustar os demais nutrientes, o que resulta na correta formulação dietética. Segundo Silva (2002), é comum o nutricionista formular rações baseando-se nas recomendações das tabelas publicadas nos Estados Unidos (NRC, 1994), na Europa (ARC, 1975) e no Brasil (ROSTAGNO et al., 2011) ou em manuais de alimentação e manejo de linhagens comerciais fornecidos pelos produtores do material genético.

No entanto, é necessário dar maior atenção às interações entre os fatores que interferem na adequada nutrição desses animais e avaliar as condições em que as tabelas são obtidas. Dessa forma, torna-se, importante considerar as relações entre o desempenho, a temperatura ambiente e a energia dietética, como a variação dos níveis de proteína e fontes de energias, para se maximizar a produção em condições climáticas distintos, observandose que as necessidades energéticas precedem às exigências dos demais nutrientes.

Quando expostas ao calor as aves apresentam uma redução do consumo de ração, o que associado ao baixo teor de proteína da ração pode gerar deficiência de aminoácidos essenciais, suficiente para prejudicar o desempenho (GERAERT et al., 1996).

Sendo o milho a principal fonte energética, e o farelo de soja a fonte protéica, os principais ingredientes utilizados nas rações de frangos de corte no 
SILVA, M.C.M. et al. Densidades nutricionais para frangos de corte estressados por calor cíclico. PUBVET, Londrina, V. 7, N. 6, Ed. 229, Art. 1517, Março, 2013.

Brasil. Há ainda a possibilidade de inclusão do óleo vegetal como fonte adicional de energia, que é utilizado nas rações para aumentar a densidade energética, promovendo efeito benéfico no desempenho dos frangos, muitas vezes apresentando valor biológico superior ao esperado.

O uso de soja extrusada, por exemplo, produz os efeitos chamados "Efeitos extra calóricos das gorduras". Estes efeitos constituem basicamente na melhora da absorção de vitaminas lipossolúveis (vitaminas A, D, E, K), diminuição na taxa de passagem dos alimentos pelo trato digestivo, propiciando, maior tempo para atuação de enzimas e absorção de nutrientes. Esse benefício ou efeito extra calórico geralmente reflete em melhoria na taxa de crescimento, na utilização dos nutrientes da ração e no seu conteúdo de energia metabolizável (SAKOMURA et al., 2004).

Devido as suas características nutritivas e à alta qualidade protéica, aliada à alta concentração energética, a soja integral passou a ser considerada como importante matéria-prima na fabricação de rações para aves. Contudo, para utilizá-la nas rações de monogástricos, é necessário processá-la para inativar os fatores antinutricionais presentes no grão da soja crua e à manutenção das suas qualidades nutritivas. Dentre estes fatores, foram identificados como termolábeis, os inibidores de tripsina e hemaglutininas; como fatores goitrogênicos, a lipoxigenase, as antivitaminas e os fitatos; como fatores termorresistentes, as saponinas e os estrógenos; e como fatores de flatulência, as lisoalaninas e os alergênicos (SAKOMURA, 1998).

O tipo de processamento da soja integral, além de reduzir os fatores antinutricionais, também influencia a digestibilidade dos polissacarídeos nãoamiláceos (PNA), da proteína e dos lipídios. Vários estudos têm demonstrado que a soja integral extrusada apresenta maior digestibilidade desses nutrientes do que a soja autoclavada ou a tostada (SAKOMURA, 1996). Essa melhora na digestibilidade decorre da maior exposição dos nutrientes à ação enzimática e da redução da viscosidade (ALONSO et al., 2001; MARSMAN et al., 1997; WHITE et al., 1967). 
Jorge Neto (1992) relaciona alguns métodos de processamentos da soja integral: tostagem por tambor rotativo, tostagem por vapor úmido, tostagem por vapor seco, micronização, extrusão úmida ou seca e microondas. De acordo com WALDROUP (1982), os principais métodos de processamento da soja integral para uso comercial são a extrusão e a tostagem. SMITH (1976) define a extrusão como um processo em que materiais úmidos, amiláceos e proteínosos, são plasticizados e cozidos por meio de uma combinação de pressão, calor e cisalhamento mecânico. A gelatinização dos componentes amiláceos, a desnaturação das proteínas e o cisalhamento e restruturação de produtos expandidos resultam dos efeitos combinados de elevada temperatura, pressão e cisalhamento mecânico dentro do cilindro extrusor.

À medida que se aumenta a densidade de nutrientes na ração pode-se obter uma melhora no desempenho zootécnico, por outro lado isso não significa melhora no resultado econômico de empresas avícolas, inviabilizando também o uso desta prática para os pequenos produtores. Dentre outros fatores para melhorar a produção de frangos de corte, além da densidade nutricional, o meio ambiente/climatização também é importante, pois ele pode exercer maior influência sobre os resultados zootécnicos, e consequentemente sobre seus custos de produção.

Encontrar o nível ótimo de energia para melhorar o desempenho e alcançar retorno econômico é um grande desafio, pois as respostas, inclusive a qualidade de carcaça, variam neste contexto. Por isso, são relevantes os estudos visando definir os efeitos dos níveis de energia e do estresse calórico para frangos de corte, principalmente em regiões de grandes variações climáticas.

\section{Consideração Final}

Com a constante procura da produção animal intensiva por alternativas para reduzir seus custos de produção, intensos esforços têm sido realizados a fim de buscar alternativas que permitam melhorar a eficiência no uso das rações, 
SILVA, M.C.M. et al. Densidades nutricionais para frangos de corte estressados por calor cíclico. PUBVET, Londrina, V. 7, N. 6, Ed. 229, Art. 1517, Março, 2013.

principalmente em regiões sem estações definidas e com temperaturas elevadas na maior parte do ano. No passado, a principal finalidade da produção avícola consistia na obtenção de ótimo peso ao abate, associado à melhor conversão alimentar. Hoje, existem, além dos citados, outros critérios importantes, como rendimento e qualidade de carcaça, produção de carne de peito, coxa, entre outros cortes. Com essa especificidade, o setor adotou novos critérios de manejo e nutrição dos frangos de corte, a fim de maximizar a produtividade e aperfeiçoar os custos. Assim, trabalhos desenvolvidos em condições de temperaturas de desconforto térmico para as aves, são viáveis pois favorecendo o acesso ao maior volume de informações sobre o tema.

\section{Referências Bibliográficas}

ALBINO, L.F.T. ROSTAGNO, H. S. TAFURI, M.L. et al. Determinação dos valores de energia metabolizável aparente e verdadeira de alguns alimentos

para aves usando diferentes métodos. Revista Brasileira Zootecnia. v. 21,p. 1047-1058, 1992.

ALONSO, R.; RUBIO, L.A.; MUZQUIZ, M. et al. The effect of extrusion cooking on mineral bioavailability in pea and kidney bean seed meals. Animal Feed Science and Technology, v.94, n.1-2, p.1-13, 2001.

AMUTHA, R.A.; SAMINATHAN, P. [2003]. Feeding of revolutionized. Nutrion \& Feeding. Disponível em:<http://www.google.com/search?q=cache:RK8P8sW1woQJ:

poultrysolutions.com/knowledg/articles/nutriti/art-2.htm+amutha+e+saminathan\&hl =ptBR\&gl=br\&ct $=$ clnk\&cd=1>. Acesso: Fev. 03, 2003.

ARAÚJO, L.F.; JUNQUEIRA, O.M.; ARAÚJO, C.S.S. et al. Proteína bruta e proteína ideal para frangos de corte no período de 1 a 21 dias de idade. Revista Brasileira de Ciência Avícola, v.3, n.2, p.157-162, 2001.

ARC. Agricultural Research Council. The nutrient requirements of poultry farm livestock. n.1. London, 1975. 154p.

BARBOSA FILHO, J.A.D.; VIEIRA, F.M.C.; SILVA, I.J.O. Transporte de frangos: Caracterização do microclima da carga durante a estação de inverno. Revista Brasileira de Zootecnia. V.38, p.2442-2446, 2009.

BARBOSA, F.J.V.; LOPES, J.B.; FIGUEREDO, A.V. et al. Níveis de energia metabolizável em rações para frangos de corte mantidos em ambiente de alta temperatura. Revista Brasileira de Zootecnia, v.37, n.5, p.849-855, 2008.

BARNWELL, R.; ROSSI, A. Maximização da performance em períodos quentes. Avicultura Industrial, v.11, p.72-80, 2003. 
BRASIL, Ministério da Agricultura. Brasília; 2011. Aves. Disponível em:<http://www.agricultura.gov.br/animal/especies/aves>. Acesso em: Jan. 12, 2011.

BRITO, B. S., ALBINO, L. F. T., ROSTAGNO, H. S., Adição de complexo multienzimático em dietas à base de soja extrusada e desempenho de pintos de corte. Revista Brasileira de Zootecnia, v.35, n.2, p. 456-461, 2006.

GERAERT, P.A., PADILHA, J.C.F., GUILLAUMIN, S.. Metabolic and endocrine changes induced by chronic heat exposure chickens: biological and endocrinological variables. British Journal of Nutrition, v.75 p.205-216, 1996.

JORGE NETO, G. Soja integral na alimentação de aves e suínos. Avicultura Industrial, n.998, p.4-15, 1992.

KESSLER, A.M.; SNIZEK JÚNIOR, P.N. Considerações sobre a quantidade de gordura na carcaça do frango. In: MATTOS, W.R.S. (Org.). A produção animal na visão dos brasileiros. Piracicaba: Fealq, 2001. p.111-133.

LANA, A.M.Q.; SILVA JUNIOR, R.G.C.; VALERIO, S.R. et al. Efeito da densidade e de programas de alimentação sobre o desempenho de frangos de corte. Revista Brasileira de Zootecnia, v.30, n.4, p.1258-1265, 2001.

LIN, H.; JIAO, H.C.; BUYSE, J. et al. Strategies for preventing heat stress in poultry. World's Poultry Journal, v.62, n.1, p.71-85, 2006.

MARSMAN, G.J.P.; GRUPPEN, H.; VAN DER POEL, A.F.B. et al. The effect of thermal processing and enzyme treatments of soybean meal on growth performance, ileal nutrient digestibilities, and chyme characteristics in broiler chicks. Poultry Science, v.76, n.6, p.864-872, 1997.

MAYNARD, L.A. et al. Nutrição animal. 3.ed. Rio de Janeiro: Freitas Bastos. 1984. 726p.

MOURA, D. J. Ambiência na avicultura de corte. In: SILVA, I. J. O. Ambiência na produção de aves em clima tropical. Piracicaba: FUNEP, 2001. p.75-149.

NATIONAL RESEARCH COUNCIL - NRC. Nutrient requirements of poultry. 9.ed. Washington, D.C.: National Academy of Sciences, 1994. 155p.

NATIONAL RESEARCH COUNCIL - NRC. Nutritional energetics of domestic animals and glossary of energy terms. 2 ed. Washington: National Academy Press.1982.54p.

NICHOLSON, F.A.; CHAMBERS, B.J.; WALKER, A.W. Ammonia emissions from broiler litter and laying hen manure management systems. Biosystems Engineering, v.89, n.2, p.175-185, 2004.

OLIVEIRA NETO, A.R.; OLIVEIRA, R.F.M.; DONZELE, J.L. et al. Densidades nutricionais metabolizável para frangos de corte no período de 22 a 42 dias de idade mantidos em ambiente termoneutro. Revista Brasileira de Zootecnia, v.29, n.5, p.1132-1140, 2000.

OLIVEIRA, G. A.; OLIVEIRA, R.F.M.; DONZELE, J.L. et al.Efeito da temperatura ambiente sobre o desempenho e as características de carcaça de frangos de corte dos 22 aos 42 dias. Revista Brasileira de Zootecnia. v. 35, n. 4, p. 1398-1405, 2006.

PEARSON, R.A.; HERRON, K.M. Effects of energy and protein allowances during lay on the reproductive performance of broiler breeders. British Poultry Science, v.22, p.227-239, 2002.

ROSTAGNO, H.S. ALBINO, L.F.T. DONZELE, J.L et al. Tabelas brasileiras para aves e suínos: composição de alimentos e exigências nutricionais. 3 ed. Viçosa: UFV, Departamento de Zootecnia, 2011. 252p.

SAKOMURA, N. K. Estudo do valor nutricional das sojas integrais processadas e de sua utilização na alimentação de frangos e poedeiras. 1996. 178p. Tese. Faculdade de Ciências Agrárias e Veterinárias, UNESP, Jaboticabal, 1996. 
SAKOMURA, N. K.; SILVA, R.; LAURENTZ, A. C. et al. Avaliação da soja integral tostada ou extrusada sobre o desempenho de frangos de corte. Revista Brasileira de Zootecnia, v.27, n.3, p.584-594, 1998.

SAKOMURA, N.K.; LONGO, F.A.; RABELLO, C.B. et al. Efeito do nível de energia metabolizável da dieta no desempenho e metabolismo energético de frangos de corte. Revista Brasileira de Zootecnia, v.33, p.1758-1767, 2004.

SAKOMURA, N.K.; ROSTAGNO, H.S. Métodos de pesquisa em nutrição de monogástricos. Jaboticabal: Funep, 2007, 283p.

SILVA, R. G. Termorregulação. In: Introdução à bioclimatologia animal. São Paulo, Nobel, 2000. p.286

SILVA JUNIOR., R.G.C.; CORDEIRO, E.C.G.; LANA, G.R.Q. et al. Exigência nutricional de energia metabolizável para frangos de corte na fase final. In: REUNIÃO ANUAL DA SOCIEDADE BRASILEIRA DE ZOOTECNIA, 39. 2002, Olinda. Anais... Recife: Universidade Federal Rural de Pernambuco, 2002. (CD-ROM).

SILVA, C. S.; COUTO, H.P.; FERREIRA, R.A. et al. Valores nutricionais de milhos de diferentes qualidades para frangos de corte. R. Bras. Zootec., v.37, n.5, p.883-889, 2008.

SILVA, D.J.; QUEIROZ, A.C. Análise de alimentos: métodos químicos e biológicos. 3.ed.Viçosa: MG: Editora UFV, 2002. 165p.

SMITH, O.B. Why extrusion looking? Cereal Food World, v.21,p.4-8, 1976.

TAO, X.; XIN, H. Acute synergistic effects of air temperature, humidity, and velocity on homeostasis of market-size broilers. Transactions of the ASAE, v. 46, n. 2, p. 491-497, 2003.

UBABEF - UNIÃO BRASILEIRA DE AVICULTURA. Relatório Anual - 2010. São Paulo. UBABEF, 2011.

WALDROUP, P.W. Influence of environmental temperature on protein and amino acid needs of poultry. Federation Proceedings, v.41,p.2821-2823,1982.

WELKER, J.S.; ROSA, A.P.; MOURA, D.J. et al. Temperatura corporal de frangos de corte em diferentes sistemas de climatização. Revista Brasileira de Zootecnia, v.37, n.8, p.1463$1467,2008$.

WHITE, C.L., GREENE, D.E., WALDROUP, P.W. et al. The use of unextracted soybeans for chick. 1 - Comparison of infra-red cooked, autoclaved and extruded soybeans. Poultry Science, v.46, p.1180-5, 1967. 